\title{
Heterotopic ossification in a patient with diffuse idiopathic skeletal hyperostosis: Input from histological findings
}

\author{
Caterina Licini, $, 1,2 *$ Luca Farinelli, ${ }^{1 *}$ Giorgia Cerqueni, ${ }^{1}$ Andrell Hosein, ${ }^{1}$ Saverio Marchi, ${ }^{1}$ Antonio Gigante, \\ Monica Mattioli-Belmonte ${ }^{1}$ \\ ${ }^{1}$ Department of Clinical and Molecular Sciences-DISCLIMO, Università Politecnica delle Marche, Ancona \\ ${ }^{2}$ Department of Applied Sciences and Technology (DISAT), Politecnico di Torino, Turin, Italy \\ *Both authors equally contributed to the work
}

\begin{abstract}
A high incidence of heterotopic ossification (HO) has been reported in patients with diffuse idiopathic skeletal hyperostosis (DISH), a metabolic disease characterized by calcifications of entheses at spine and peripheral sites. We performed histological and immunohistochemical analyses in five different $\mathrm{HO}$ sites in a patient with DISH to study a possible mutual interaction of bone morphogenetic protein 2 (BMP-2), transforming growth factor beta (TGF- $\beta$ ), and decorin, crucial for bone mass increasing, matrix calcification, and endochondral bone formation. We speculated that the surgical trauma triggered HO, inducing TGF- $\beta$ release at the lesion site. TGF- $\beta$ recruits osteoblast precursor cells and determines the overexpression of BMP-2 in the surrounding skeletal muscle, inducing a further osteogenic differentiation, contributing to $\mathrm{HO}$ onset.
\end{abstract}

Key words: heterotopic ossification; DISH; BMP-2; TGF-beta; decorin.

Correspondence: Monica Mattioli-Belmonte, Department of Clinical and Molecular Sciences-DISCLIMO, Università Politecnica delle Marche, Via Tronto 10/A, 60126 Ancona, Italy. Tel. +39.071.2206077.

E-mail:m.mattioli@univpm.it

Contributions: LF, CL data collection and analysis; CL, GC, AH, experimental procedure: LF, CL, SM, MMB, data interpretation; LF, CL, MMB, manuscript drafting. All the authors have read and approved the final version of the manuscript and are responsible for the integrity of the data analysis.

Conflict of interest: Each author certifies that he or she has no commercial associations (e.g., consultancies, stock ownership, equity interest, patent/licensing arrangements, etc.) that might pose a conflict of interest in connection with the submitted article.

Availability of data and materials: The data used to support the findings of this study are available from the corresponding author upon request.

Ethics approval and consent to participate: All procedures performed in studies involving human participants were in accordance with the ethical standards of the Institutional Research Committee and with the 1964 Helsinki declaration and its latest amendment. Written informed consent was obtained from the patient.

Patient consent for publication: The patient gave his written consent to use his personal data for the publication of this case report and any accompanying images. 


\section{Introduction}

Diffuse idiopathic skeletal hyperostosis (DISH) is a metabolic pathology characterized by calcifications and ossifications of the entheses associated with cardiovascular disorders and several metabolic factors, such as obesity, diabetes and hyperinsulinemia. ${ }^{1-3}$ Approximately, $30 \%$ of patients affected by DISH develop serious heterotopic ossification (HO) following a hip replacement. 4,5

$\mathrm{HO}$ process is triggered by inflammation after surgery: immune cells infiltrate the site of the future ossification, releasing growth factors that contribute to recruiting mesenchymal stem cells (MSCs). These cells differentiate into chondrocytes, which will undergo hypertrophy, leading to ossification and blood vessel formation. ${ }^{1,5-7}$ We investigated the expression of bone morphogenetic protein 2 (BMP-2) and transforming growth factor $\beta$ (TGF$\beta$ ), two members of the TGF- $\beta$ protein family that favour the increase of bone mass and bone matrix calcification, and decorin, a proteoglycan widely expressed during endochondral bone formation. These molecules and their mutual interaction represent critical factors in ectopic bone formation, ${ }^{2,6-12}$ contributing to $\mathrm{HO}$ pathophysiology. ${ }^{3-16}$ Here we reported a morphological investigation performed in a subject where, after lumbosacral X-ray and right hip computed tomography (CT) analyses and according to Resnick and Niwayama's criteria, ${ }^{17}$ we have diagnosed DISH. Our histological and immunohistochemical assessment analysed the possible molecular relationship between DISH and HO onset.

\section{Materials and Methods}

\section{Patient and tissue collection}

A 70-year-old man with a history of hypertension, diabetes mellitus, stroke and ischemic cardiomyopathy, underwent elective right hip arthroplasty in June 2016. The post-surgical course was regular. After a few weeks, during rehabilitation, he started to complain about a severe limitation of hip motion. In May 2019, the patient came to our observation with a 3-year history of slowly progressive, restricted right hip joint motion. Lumbosacral X-ray and right hip CT showed ossification along both right- and left-side anterolateral borders of 3 contiguous vertebrae (T10 to T12) and a HO mass located mainly along with iliopsoas muscle, piriform, and middle gluteus (Figure 1). After the surgical procedure for the removing of the right hip motion limitation, tissues from five different HO sites were obtained. Following the Local Ethical Committee guidelines and the 1964 Helsinki declaration, informed consent was obtained.

\section{Histological and immunohistochemical analyses}

Tissue specimens were fixed in $4 \%$ neutral buffered formaldehyde solution for $48 \mathrm{~h}$, decalcified by Biodec R (Bio-Optica, Milan, Italy) for $6 \mathrm{~h}$ and then routinely processed for paraffin embedding. Six- $\mu$ m-thick paraffin-embedded tissue sections were deparaffinized and rehydrated with xylene and a graded series of ethyl alcohols, and stained by Haematoxylin and Eosin (H\&E), Toluidine Blue or Safranin O.

For immunohistochemistry, deparaffinized and rehydrated slides were incubated with $3 \%$ hydrogen peroxide for 30 min to block endogenous peroxidase activity. Antigen retrieval was performed in Citrate buffer $\mathrm{pH} 6$ at $70^{\circ} \mathrm{C}$ for $10 \mathrm{~min}$ (BMP-2 and Decorin) and in $0.3 \%$ Tween 20 in $1 x$ PBS at RT for $20 \mathrm{~min}$ (TGF- $\beta$ ). Sections were then incubated overnight at $4{ }^{\circ} \mathrm{C}$ with antiBMP-2 (ab14933, Abcam, Cambridge, UK; $1: 250$ ), anti-TGF- $\beta$ (GTX21279, GeneTex, Irvine, CA, USA; 1:200) or anti-decorin (ab175404, Abcam; 1:400) antibodies. Antigens were visualized by Envision Dako REAL ${ }^{\mathrm{TM}}$ EnVision ${ }^{\mathrm{TM}}$ Detection System (K5007, Dako, Santa Clara, CA, USA). Sections were counterstained with Mayer's haematoxylin, dehydrated, and mounted in Biomount HM (Bio-Optica). Healthy bone was used as positive control. Omission of primary antibody and muscle biopsies were used as negative controls.

\section{Immunostaining evaluation}

ImageJ software (https://imagej.nih.gov/ij/) was used to analyse the percentage of the staining area, on four different images at 20x magnification from each tissue sample. Briefly, after color deconvolution to examine only DAB staining, bone tissue was selected as Regions of Interest (ROI) and the area percentage was calculated. Statistical analyses were performed using GraphPad Prism 7 software (https:/www.graphpad.com/scientific-software/ prism/). Mann-Whitney test was used to compare the groups. A p-value $<0.05$ was considered significant.

\section{Results}

The different HO sites showed a tissue mainly composed of compact and trabecular bone, with a notable portion of woven bone and a high number of osteocyte lacunae. Several osteoclasts were located at the ossification site. A bone marrow-like structure, blood vessels, connective tissue and muscle fibre residues in the HO mass were observed. Toluidine Blue and Safranin O staining pointed out the presence of cartilage, not only at the ossification site, and the abundance of proteoglycans in the bone matrix, especially in woven bone (Figure 2).

BMP-2 immunohistochemical staining in $\mathrm{HO}$ was of $5.023 \% \pm 0.25$ in woven bone, and it significantly $(\mathrm{P}=0.002)$ decreased to $0.254 \% \pm 0.05$ in the lamellar bone (Figure $3 \mathrm{~A}, \mathrm{a}-\mathrm{c}$ ) High BMP-2 expression was detected in the muscle tissue from the resected fragments (HO 79.575\% $\pm 13.09 v s$ healthy $0.49 \% \pm 0.05$, $\mathrm{P}=0.002$ ) (Figure 3A,d-f), cartilage matrix and chondrocytes at the ossification site. Approaching bone formation sites, BMP-2 expression decreased. Osteoclasts (Figure 3B) and endosteum (Figure 3A,b) were also greatly positive for BMP-2.

Woven and lamellar bone tissues displayed abundant spots of TGF- $\beta$ stain in ECM (Figure $3 \mathrm{Ag}-\mathrm{i}$ ). At the ossification site, cartilage matrix displayed a strong TGF- $\beta$ expression that decreases approaching the bone tissue. All chondrocytes were weakly stained (Figure 3B).

Decorin staining was present along lamellae and, at a higher amount, in the woven bone (Figure $3 \mathrm{~A}, \mathrm{j}-1$ ) It was also highly expressed in cartilage matrix but not in chondrocytes and, as the bone formation site was approached, chondrocytes expressed decorin while cartilage lost staining (Figure 3B).

\section{Discussion}

DISH represents a predisposing factor for the formation of ectopic calcification in the first months following total hip arthroplasty. ${ }^{4,5}$ Due to soft tissue trauma, inflammatory cells infiltrate the site of future ossification, release abundant growth factors, inducing $\mathrm{HO}$ development. ${ }^{6}$ Here we investigated the histological features, and the expression and localization of BMP-2, TGF- $\beta$ and decorin in HO samples from a DISH patient, to evaluate possible molecular crosstalk. Histological sections displayed a well-structured ectopic compact and trabecular bone, formed by endochondral ossification, rich in blood vessels and 
containing bone marrow. The abundant woven bone and cartilage, the high proteoglycan content in woven bone, and the presence of several osteoclasts suggested that the HO process was still ongoing. ${ }^{17,18}$ The dissimilar immunohistochemical distribution of BMP-2, TGF- $\beta$ and decorin implies their different contribution to HO development. BMP-2 is involved in the differentiation of MSCs into osteoblasts and regulates early osteoblast gene expression. ${ }^{9}$ Changes in BMP-2 expression in woven and lamellar bones and its decrease in cartilage matrix and chondrocytes coming close to the bone formation site support the idea that BMP-2 exerts a key role in the early stages of bone formation in $\mathrm{HO}^{10-12,20-22}$ also in DISH patients. BMP-2 is also involved in osteoclast progenitor differentiation and osteoclast survival, ${ }^{23,24}$ and its high expression in osteoclasts at ossification sites suggests the contribution to cartilage resorption during bone formation. Elevated BMP-2 staining was also observed in muscular tissues contiguous to the HO sites. Several studies revealed that BMP-2 induces chondrogenic and osteogenic differentiation and endochondral ossification in MSCs from skeletal muscle, and in tendon-derived cells. Moreover, BMP-2 allows fibroblasts, myoblasts, and bone marrow stromal cells to reverse-differentiate into osteoblasts. ${ }^{13,20,21,25,26}$ TGF- $\beta$ leads to the migration and differentiation of bone MSCs and stimulates the synthesis of structural ECM proteins, ${ }^{27,28}$ playing a crucial role in bone homeostasis. ${ }^{5}$ In bone ECM, TGF- $\beta$ is stored as a latent form and becomes active during bone resorption before being released in the blood stream. TGF- $\beta$ begins its action during the initial inflammation stage of $\mathrm{HO}$, when it is released by immune cells that migrate at the future ossification site favouring MSCs recruitment. ${ }^{6,27,29,30} \mathrm{We}$ observed several spots of TGF- $\beta$ in both lamellar and woven bone; however, the presence of osteoclasts suggests its release and activation, encouraging the HO progression. Decorin, primarily involved in Type I collagen assembly and calcium deposition, is extensively expressed during endo-
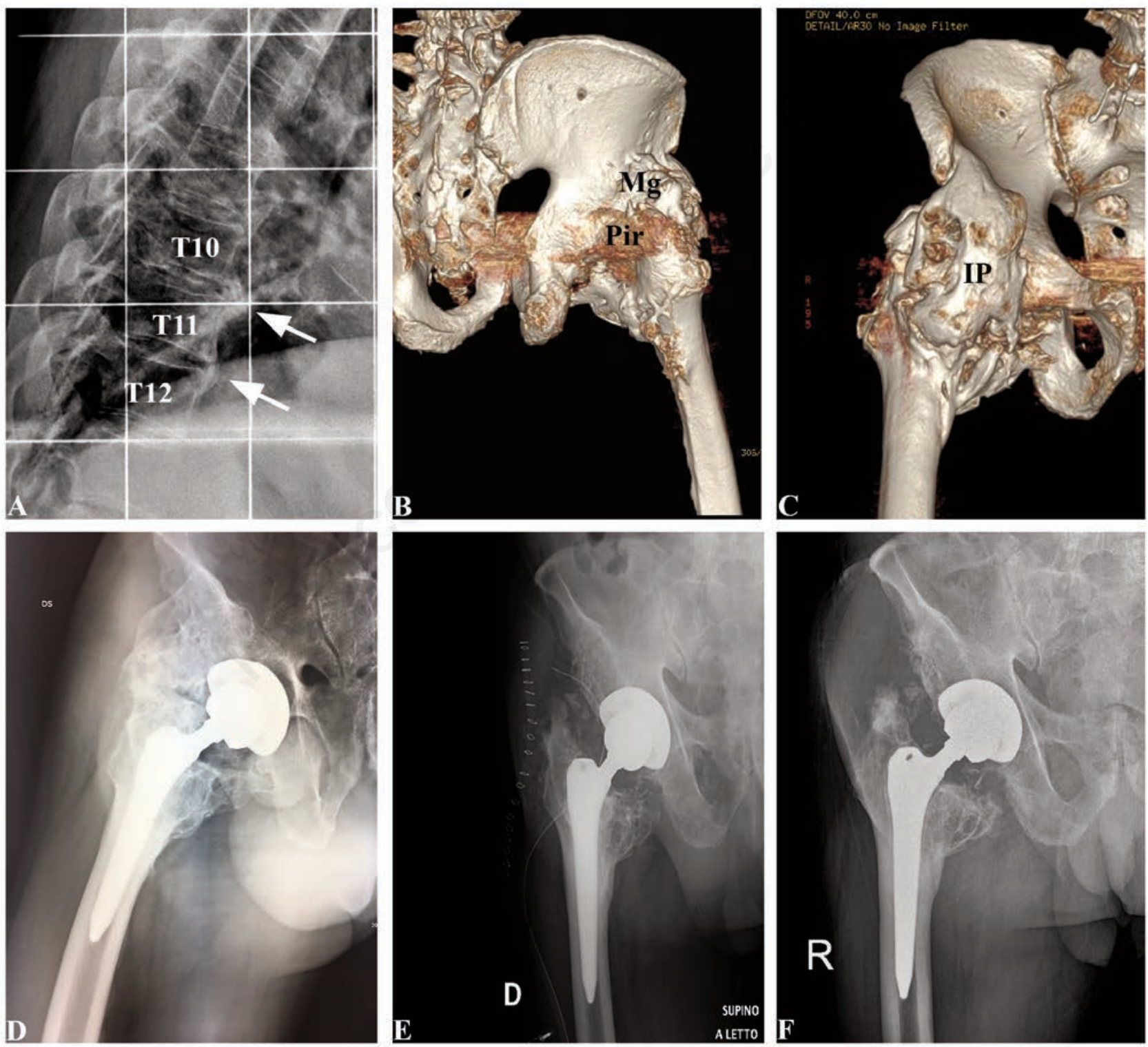

Figure 1. Radiological and CT evidence of HO around the hip. A) Pre-operative X-rays image showing bridging ossification along T10, T11 and T12 vertebrae. B,C) Pre-operative CT images; IP, ilio-psoas; Mg, medius gluteus; Pir, piriformis. D) Pre-operative X-rays image showing $\mathrm{HO}$ at right hip. E) X-rays image taken at 1 day after surgery. e) X-rays image taken at 8 weeks after surgery. 
chondral bone formation, mainly in the osteoid, revealing the immature stage of bone tissue. ${ }^{15,31}$ Here, the high staining for decorin in the woven bone supports its role in the organization and maturation of ECM during HO. Moreover, decorin may also bind active TGF- $\beta$, enhancing its activity in bone formation and remodelling. ${ }^{15,2}$ Despite the limitation of a case-report study, our results are consistent with the existing literature on the role of osteo-inductive signaling in the formation of ectopic bone. ${ }^{6,32} \mathrm{We}$ can speculate that the surgical trauma (e.g., hip replacement) in patients affected by DISH triggers a release of TGF- $\beta$ by inflammatory cells that induce the migration of bone MSCs to the future $\mathrm{HO}$ sites and contributes to their differentiation into chondrocytes. Concomitantly, the high BMP-2 levels in the surrounding skeletal muscle cooperate to induce osteogenic differentiation. Additional studies are still necessary to unravel the functional crosstalk between tissues and growth factors in HO physiopathology, to open for potential molecular therapeutic approaches ${ }^{33}$ to prevent and/or limit the HO onset in patients affected by DISH.
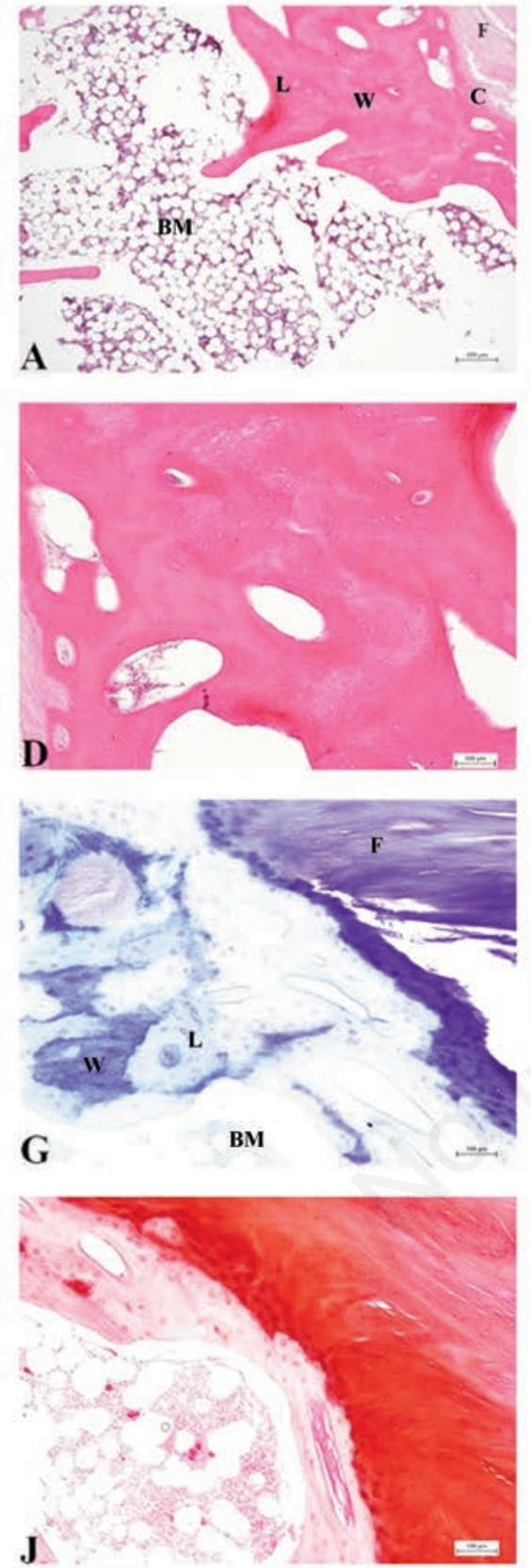
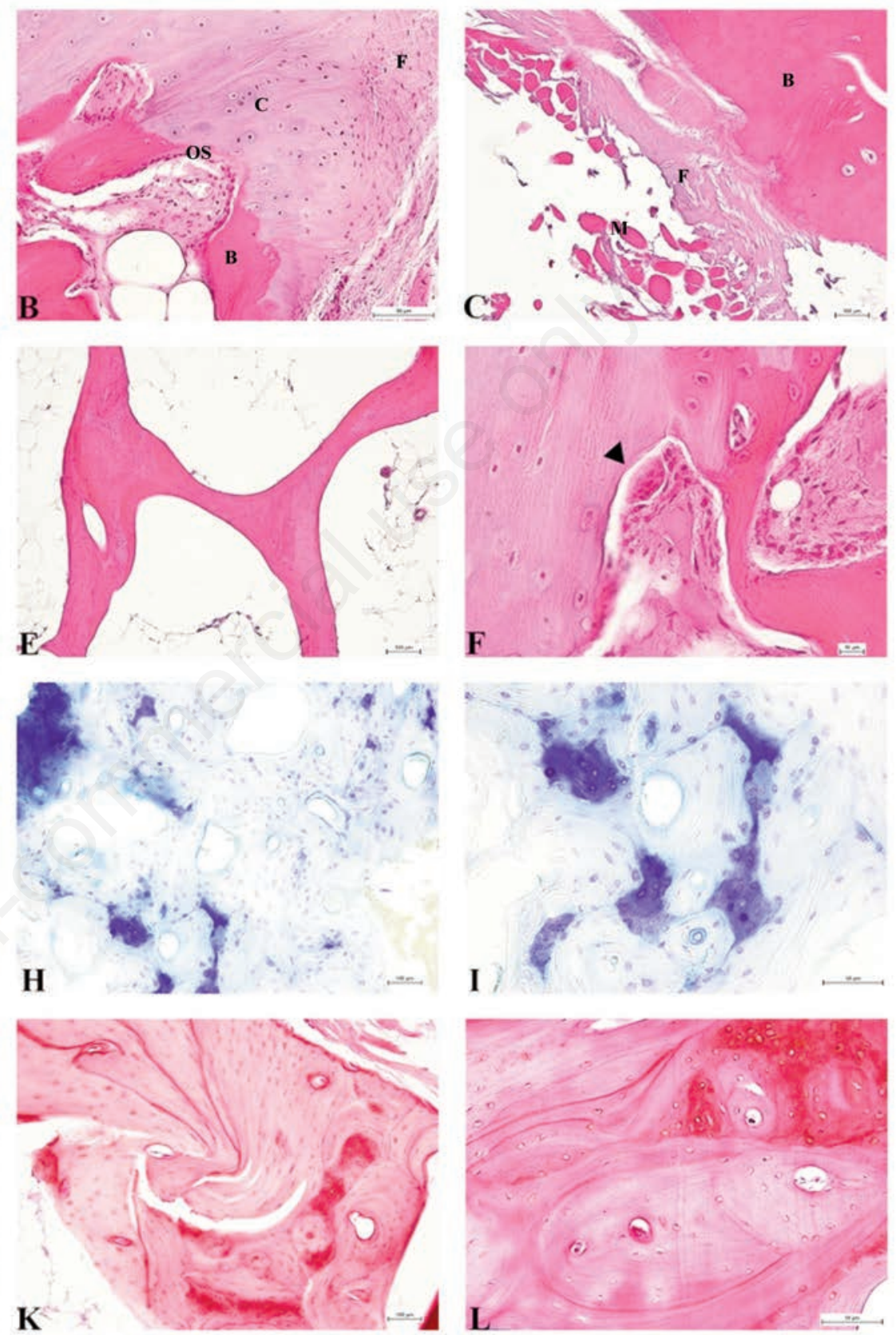

Figure 2. A-F) Haematoxylin \& Eosin staining of HO. A) Compact bone with adjacent cartilage layer. Fibrous tissue and bone marrow are also shown; scale bar $100 \mu \mathrm{m}$. B) Ossification site; scale bar $50 \mu \mathrm{m}$. C) Muscular and fibrous tissues adjacent to bone; scale bar 100 $\mu \mathrm{m}$. D) Compact bone; scale bar $100 \mu \mathrm{m}$. E) Trabecular bone; scale bar $100 \mu \mathrm{m})$.F) Particular of ossification site, black arrowheads indicate osteoclasts; scale bar $10 \mu \mathrm{m}$. G-I) Toluidine Blue staining; blue colour indicates high proteoglycan content. G) Compact bone with adjacent cartilage layer; scale bar $100 \mu \mathrm{m}$. H) Compact bone; scale bar $100 \mu \mathrm{m}$. I) Particular of compact bone; scale bar $50 \mu \mathrm{m}$. $\mathrm{J}-\mathrm{L})$ Safranin $\mathrm{O}$ staining; red colour indicates high proteoglycan content. J) Compact bone with adjacent cartilage layer; scale bar 100 $\mu \mathrm{m}$. K) Compact bone; scale bar $100 \mu \mathrm{m}$. L) Particular of compact bone; scale bar $50 \mu \mathrm{m}$; W, woven bone; L, lamellar bone; B, bone; $\mathrm{C}$, cartilage; BM, bone marrow; M, muscular tissue; F, fibrous tissue; OS, ossification site. 
A BMP-2
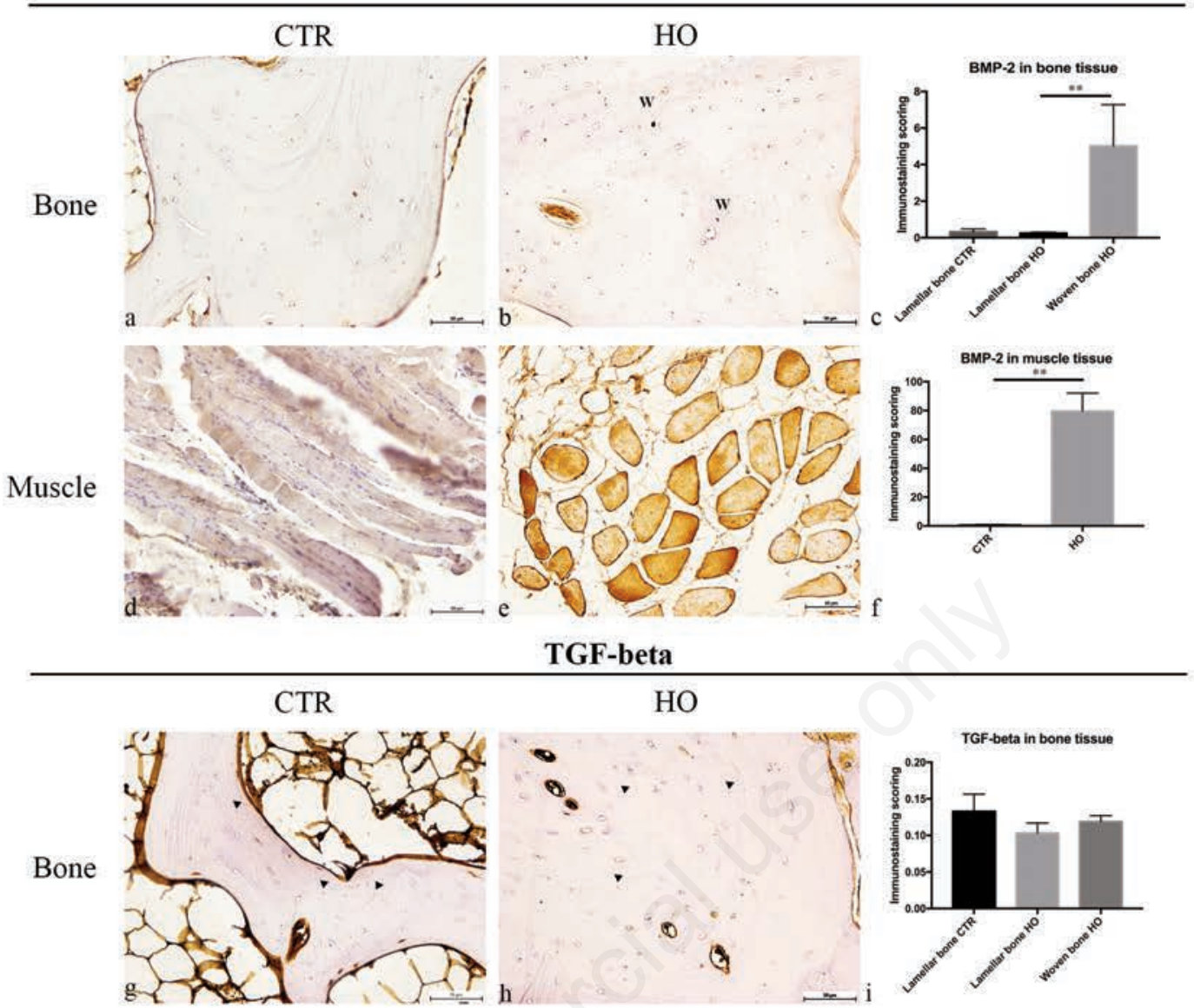

Decorin

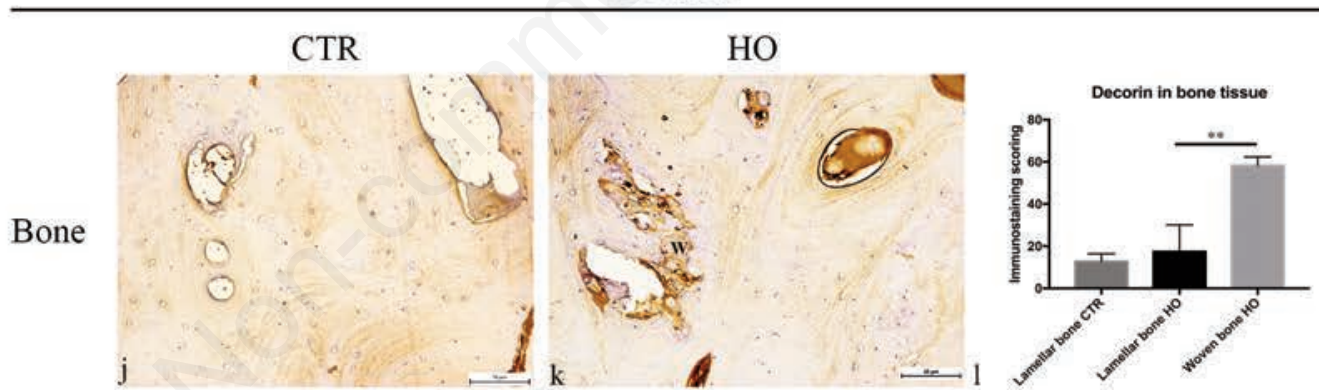

B

BMP-2

TGF-beta

Decorin

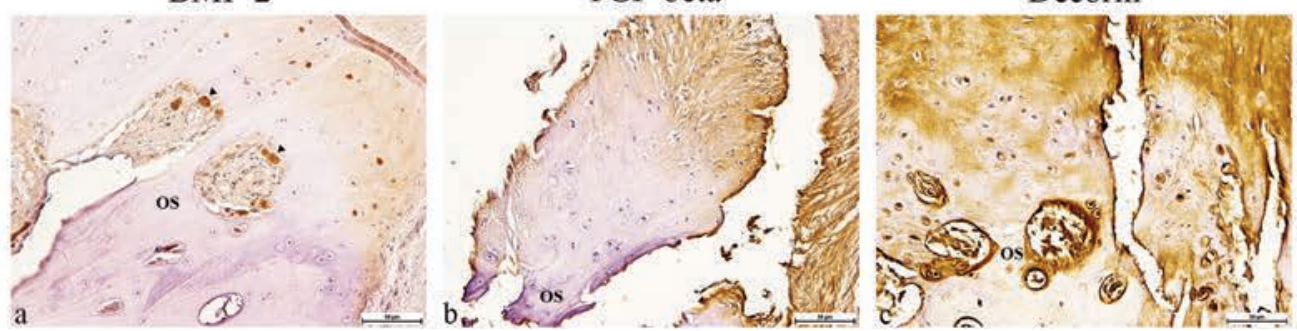

Figure 3. A) Immunohistochemical analysis of BMP-2, TGF-beta and decorin in healthy and HO tissues; scale bar 50 um; BMP-2 staining in (a) healthy lamellar bone, (b) HO lamellar and woven bone (W), and (c) representative histogram of BMP-2 expression $\left({ }^{* *} \mathrm{p}<0.01\right)$; BMP-2 expression in (d) healthy and e) HO muscular tissue, and (f) representative histogram of BMP-2 expression $\left({ }^{* *} \mathrm{p}<0.01\right)$; TGF-beta staining in (g) healthy lamellar bone (arrowheads), (h) HO woven and lamellar bone (arrowheads), and (i) representative histogram of TGF-beta expression; decorin expression in (j) healthy lamellar bone, (k) HO woven (W) and lamellar bone, and (1) representative histogram of decorin expression $\left({ }^{* *} \mathrm{p}<0.01\right)$. B) BMP-2, TGF-beta and decorin staining in cartilage tissue in HO; a) at the ossification site (OS), BMP-2 expression in cartilage, chondrocytes and osteoclast (arrowheads) in cartilage; b) at the ossification site (OS), TGF-beta expression in cartilage and chondrocytes; c) at the ossification site (OS), decorin expression in cartilage and chondrocytes. 


\section{References}

1. Vasileiadis GI, Amanatullah DF, Crenshaw JR, Taunton MJ, Kaufman KR. Effect of heterotopic ossification on hip range of motion and clinical outcome. J Arthroplasty 2015;30:461-4.

2. Mader R, Verlaan J-J, Buskila D. Diffuse idiopathic skeletal hyperostosis: clinical features and pathogenic mechanisms. Nat Rev Rheumatol 2013;9:741-50.

3. Fournier DE, Kiser PK, Beach RJ, Dixon SJ, Séguin CA. Dystrophic calcification and heterotopic ossification in fibrocartilaginous tissues of the spine in diffuse idiopathic skeletal hyperostosis (DISH). Bone Res 2020;8:1-10.

4. Belanger TA, Rowe DE. Diffuse idiopathic skeletal hyperostosis: musculoskeletal manifestations. J Am Acad Orthop Surg 2001;9:258-67.

5. Mader R, Verlaan J-J, Eshed I, Bruges-Armas J, Puttini PS, Atzeni F, et al. Diffuse idiopathic skeletal hyperostosis (DISH): where we are now and where to go next. RMD Open. 2017;3:e000472.

6. Wang X, Li F, Xie L, Crane J, Zhen G, Mishina Y, et al. Inhibition of overactive TGF- $\beta$ attenuates progression of heterotopic ossification in mice. Nat Commun 2018;9:551.

7. Li L, Tuan RS. Mechanism of traumatic heterotopic ossification: In search of injury-induced osteogenic factors. J Cell Mol Med 2020;24:11046-55.

8. Tang Y, Wu X, Lei W, Pang L, Wan C, Shi Z, et al. TGF-beta1induced migration of bone mesenchymal stem cells couples bone resorption with formation. Nat Med 2009;15:757-65.

9. Shi L, Sun W, Gao F, Cheng L, Li Z. Heterotopic ossification related to the use of recombinant human BMP-2 in osteonecrosis of femoral head. Medicine (Baltimore) 2017;96:e7413.

10. Tachi K, Takami M, Sato H, Mochizuki A, Zhao B, Miyamoto Y, et al. Enhancement of bone morphogenetic protein-2-induced ectopic bone formation by transforming growth factor- $\beta 1$. Tissue Eng Part A 2011;17: 597-606.

11. Han XG, Wang DK, Gao F, Liu RH, Bi ZG. Bone morphogenetic protein 2 and decorin expression in old fracture fragments and surrounding tissues. Genet Mol Res 2015;14:11063-72.

12. Zhou N, Li Q, Lin X, Hu N, Liao J-Y, Lin L-B, et al. BMP2 induces chondrogenic differentiation, osteogenic differentiation and endochondral ossification in stem cells. Cell Tissue Res 2016;366:101-11.

13. Tanaka H, Nagai E, Murata H, Tsubone T, Shirakura Y, Sugiyama T, et al. Involvement of bone morphogenic protein-2 (BMP-2) in the pathological ossification process of the spinal ligament. Rheumatology (Oxford) 2001;40:1163-8.

14. Mochida Y, Parisuthiman D, Pornprasertsuk-Damrongsri S, Atsawasuwan P, Sricholpech M, Boskey AL, et al. Decorin modulates collagen matrix assembly and mineralization. Matrix Biol 2009;28:44-52.

15. Mania VM, Kallivokas AG, Malavaki C, Asimakopoulou AP, Kanakis J, Theocharis AD, et al. A comparative biochemical analysis of glycosaminoglycans and proteoglycans in human orthotopic and heterotopic bone. IUBMB Life 2009;61:447-52.

16. Bosse A, Kresse H, Schwarz K, Müller KM. Immunohistochemical characterization of the small proteoglycans decorin and proteoglycan100 in heterotopic ossification. Calcif Tissue Int 1994;54:119-24.

17. Resnick D, Niwayama G. Radiographic and pathologic features of spinal involvement in diffuse idiopathic skeletal hyperostosis (DISH). Radiology 1976;119:559-68.

18. Kuperus JS, Westerveld LA, Rutges JPHJ, Alblas J, van Rijen MHP, Bleys RLAW, et al. Histological characteristics of diffuse idiopathic skeletal hyperostosis. J Orthop Res 2017;35:140-6.

19. Huang Y, Wang X, Lin H. The hypoxic microenvironment: a driving force for heterotopic ossification progression. Cell Commun Signal 2020;18:20.

20. Ferrazzo PC, Niccoli S, Khaper N, Rathbone CR, Lees SJ. Ascorbic acid diminishes bone morphogenetic protein 2-induced osteogenic differentiation of muscle precursor cells. Muscle Nerve 2019;59:501-8.

21. Kawai M, Ohmori YK, Nishino M, Yoshida M, Tabata K, Hirota DS, et al. Determination of cell fate in skeletal muscle following BMP gene transfer by in vivo electroporation. Eur J Histochem 2107;61:2772.

22. Pulik Ł, Mierzejewski B, Ciemerych MA, Brzóska E, Łęgosz P. The survey of cells responsible for heterotopic ossification development in skeletal muscles-human and mouse models. Cells 2020;9:1324.

23. Itoh K, Udagawa N, Katagiri T, Iemura S, Ueno N, Yasuda H, et al. Bone morphogenetic protein 2 stimulates osteoclast differentiation and survival supported by receptor activator of nuclear factorkappaB ligand. Endocrinology 2001;142:3656-62.

24. Jensen ED, Pham L, Billington CJ, Espe K, Carlson AE, Westendorf $\mathrm{JJ}$, et al. Bone morphogenic protein 2 directly enhances differentiation of murine osteoclast precursors. J Cell Biochem 2010;109:672-82.

25. Sartori R, Sandri M. BMPs and the muscle-bone connection. Bone 2015;80:37-42.

26. Musgrave DS, Pruchnic R, Wright V, Bosch P, Ghivizzani SC, Robbins PD, et al. The effect of bone morphogenetic protein-2 expression on the early fate of skeletal muscle-derived cells. Bone 2001;28:499-506.

27. Licini C, Vitale-Brovarone C, Mattioli-Belmonte M. Collagen and non-collagenous proteins molecular crosstalk in the pathophysiology of osteoporosis. Cytokine Growth Factor Rev 2019;49:59-69.

28. Stabellini G, Vertemati M, Locci P, Calvitti M, Minola E, Calastrin, $\mathrm{C}$, et al. In vitro human osteoblast and extracellular matrix changes after transforming growth factor beta 1 treatment. Pathology 2005;37:347-54.

29. Zhang Q, Zhang Y, Yan M, Zhu K, Su Q, Pan J, Yang M, Zhou D, Tan J. Big-h3 enhances chondrogenesis via promoting mesenchymal condensation in rat Achilles tendon heterotopic ossification model. Aging (Albany NY) 2020;12:7030-41.

30. Zhang Q, Zhou D, Wang H, Tan J. Heterotopic ossification of tendon and ligament. J Cell Mol Med 2020;24:5428-37.

31. Bilezikian JP, Raisz LG, Rodan GA. Principles of bone biology. San Diego: Academic Press; 2002.

32. Toom A, Suutre S, Märtson A, Haviko T, Selstam G, Arend A. Lack of a central role for osteoprogenitor cells from the femoral canal in heterotopic ossification of the hip. J Bone Joint Surg Br 2010; 92:298-303.

33. Hoover ME, Martin EC, Llamas CB, Qureshi A, Davis TA, Gimble JM, Freitas MA. Proteomic characterization of a trauma-based rat model of heterotopic ossification identifies interactive signaling networks as potential therapeutic targets. J Proteomics 2020;226: 103907.

Received for publication: 28 August 2020. Accepted for publication: 27 October 2020.

This work is licensed under a Creative Commons Attribution-NonCommercial 4.0 International License (CC BY-NC 4.0).

CCopyright: the Author(s), 2020

Licensee PAGEPress, Italy

European Journal of Histochemistry 2020; 64:3176

doi:10.4081/ejh.2020.3176 